\title{
IS THERE A ROLE FOR MUSIC THERAPY IN ATTENTION DEFICIT AND HIPERACTIVITY DISORDER?
}

\author{
Duarte N. ${ }^{1}$, Ferro M. ${ }^{2}$, Rodrigues M. ${ }^{1}$, Sanchez J. ${ }^{3}$
}

1- Child and Adolescent Psychiatry Resident, Hospital Dona Estefânia of Centro Hospitalar Universitário Lisboa Central, Lisbon, Portugal

2- Neurology Resident, Hospital Santo António dos Capuchos of Centro Hospitalar Universitário Lisboa Central, Lisbon, Portugal

3- Child and Adolescent Psychiatrist, Hospital Dona Estefânia of Centro Hospitalar Universitário Lisboa Central, Lisbon, Portugal

\section{BACKGROUND}

Attention Deficit and Hyperactivity Disorder (ADHD) is one of the most prevalent psychiatric diseases affecting children. Given that sometimes it is difficult to manage with the available treatments, the ongoing debate concerning its use in the younger patients calls for different approaches. Recent findings suggest an overlap between the neural regions related with the processing of musical rhythm and those involved in ADHD, explaining their difficulty with rhythm patterns and time perception. ${ }^{1}$

These findings bring the question whether there is or not a therapeutic potential in music, when approaching children with ADHD.
MATERIALS AND METHODS

We conducted a non-systematic review of PubMed database literature using the following key words: "music", "therapy" and "ADHD".

\section{OBJECTIVES}

Our goal is to understand how can music help children struggling with the diagnosis of ADHD, perceive the strength of the evidence supporting this approach and discriminate the sub-group that can benefit the most from music therapy;

\section{RESULTS AND CONCLUSIONS}

\section{CHILDREN WITH ADHD HAVE LOWER PERFORMANCES IN MUSICAL TASKS}

Children with ADHD have worse performance in sound and musical tasks than those with normal development, with or without methylphenidate. Carrer observed in 2015 that these children have more difficulty with spontaneous time production, as well as perceiving duration and time estimation of both music and simple sounds. ${ }^{1-3}$

\section{TIME PERCEPTION}

The ability to estimate, anticipate, or perceive different intervals and durations of time.

Music and sound allow us to understand how attention and self-control are related to time perception. ${ }^{1,3}$

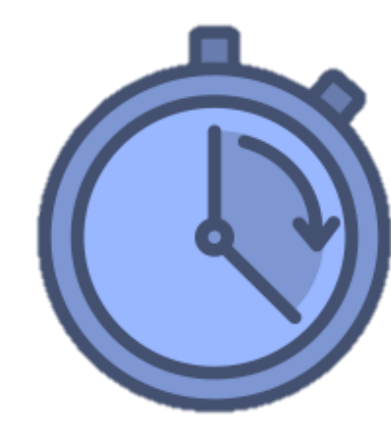

HETEROGENICITY
Skills such as beat tracking are very heterogeneous in children
with ADHD. ${ }^{2}$
Puyjarinet et al. observed that $35 \%$ of the participants with
ADHD performed as well as controls did. ${ }^{2}$

Huang et al. suggested that the time processing difficulties in children with ADHD were affected by genetics, being very sensitive to family history. They also concluded that there is no relation between time perception and comorbidities in ADHD. 3

\section{EFFECTS OF WHITE NOISE IN CHILDREN WITH ADHD}

Noise is known as being detrimental to cognitive performance. 5,6 That is not the case with children with ADHD. ${ }^{6}$
In one study, teachers ranked their students by their attention level to find out that the least attentive benefited the most from white noise therapy. On the contrary, the most attentive lowered their performances with white noise. 4

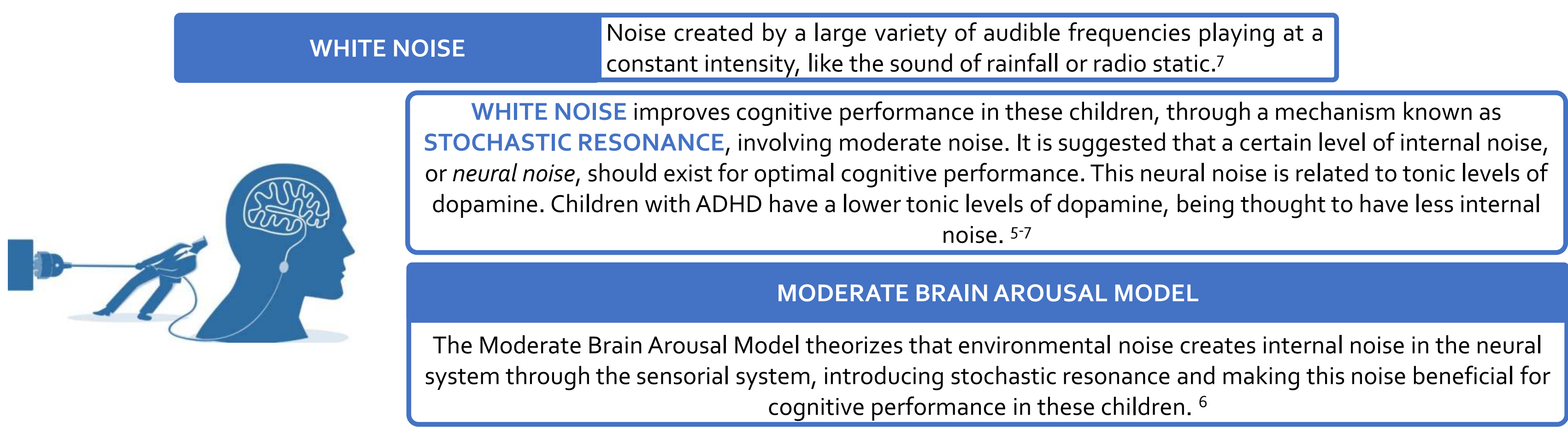

A large number of studies already suggested the benefits from white noise in these situations. ${ }^{2}$

They find that in order to take the most benefit from white noise, it should be provided BINAURALLY as meaningless noise in the range of $65-80$ DB. 7

\section{MUSIC THERAPY}

It appears that therapy with white noise is beneficial for children with ADHD in academic tasks, specially those cognitively demanding. The more inattentive the child is, more benefits he or she can gain from white noise. It is easily applicable in a classroom or at home, using headphones so it doesn't bother other children or simply playing it in the background at home. One should listen to white noise in $80 \mathrm{~dB}$ for optimal results. It can be used as complementary strategy to the pharmacological approach. 